\title{
O PARADIGMA HERMENÊUTICO COMO FUNDAMENTAÇÃO DAS PESQUISAS ETNOGRÁFICAS E FENOMENOLÓGICAS
}

\author{
Maria Cristina Pinto de Jesus* \\ Marisa Ribeiro Bastos Peixoto** \\ Mércia Heloísa Ferreira Cunha***
}

JESUS, M.C.P. de; PEIXOTO, M.R.B.; CUNHA, M.H.F. O paradigma hermenêutico como fundamentação das pesquisas etnográficas e fenomenológicas. Rev.latino-am.enfermagem, Ribeirão Preto, v. 6, n. 2, p. 29-35, abril 1998.

O estudo apresenta uma revisão da literatura sobre o paradigma hermenêutico como fundamentação das pesquisas etnográficas e fenomenológicas.

UNITERMOS: pesquisa interpretativa, hermenêtica, fenomenologia, antropologia

\section{INTRODUÇÃO}

A partir da década de 60, nos Estados Unidos e de 80 , no Brasil, observa-se na enfermagem um crescente interesse nas pesquisas interpretativas. Em decorrência disso surgem diferentes nomenclaturas e referências ontológicas e epistemológicas, dando origem a conceituações e classificações não bem definidas ou mesmo equivocadas.

Assim como afirma LOWENBERG (1993), os pesquisadores da enfermagem que adotam as abordagens qualitativas desenvolveram seus programas de pósgraduação em diferentes áreas do conhecimento, como na Sociologia, Antropologia e Psicologia, levando a uma dificuldade de delinear significados comuns em seus discursos.

$\mathrm{Na}$ fase de elaboração dos projetos para qualificação das autoras em Programas de Doutorado deparamos com a dificuldade de identificação da corrente filosófica que fundamentasse nossos pressupostos teórico-metodológicos. Nossos projetos estavam vinculados à compreensão de fenômenos situados no cotidiano da enfermagem, buscando significados atribuídos pelos sujeitos a suas experiências, num enfoque sociológico e antropológico.

Buscando definir o referencial filosófico que norteasse as nossas pesquisas - etnográfica e fenomenológica - deparamo-nos com diferentes abordagens e classificações usadas pelos autores que adotam a linha qualitativa.

Por outro lado, identificamos a escassez de trabalhos na área da Enfermagem que discutem os aspectos epistemológicos e metodológicos das abordagens interpretativas.

Acreditando não ser possível desvincular nossa visão de mundo e a intencionalidade de nossas vivências enquanto docentes e pesquisadores, realizamos uma breve revisão da literatura com o objetivo de delimitar o referencial filosófico, sociológico e antropológico que fundamentasse a elaboração dos nossos projetos de pesquisa.

\section{A HERMENÊUTICA E AS PESQUISAS INTERPRETATIVAS}

A hermenêutica é definida por BLEICHER (1992), como a teoria ou filosofia da interpretação dos sentidos. O problema hermenêutico é fundamentado na

“... percepção de que as expressões humanas contêm componente significativo, que tem que ser reconhecido como tal, por um sujeito e transposto

\footnotetext{
* Mestre em Educação. Enfermeira, doutoranda na EEUSP/EEUFMG. Professora Adjunto da Faculdade de Enfermagem da Universidade Federal de Juiz de Fora

** Doutora em Enfermagem. Enfermeira, Professora Adjunta da Escola de Enfermagem da Universidade Federal de Minas Gerais *** Mestre em Enfermagem Médico-Cirúrgica. Enfermeira, doutoranda na EEUSP/EEUFMG. Professora Adjunto da Escola de Enfermagem da Universidade Federal de Minas Gerais
} 
para o seu próprio sistema de valores $e$ significados"(BLEICHER, 1992, p. 13).

A hermenêutica tem sido utilizada como base filosófica para diferentes estudos qualitativos realizados por enfermeiros, tendo em vista que o homem e as interações humanas são freqüentemente objeto de estudo da enfermagem. Estudos de tal natureza remetem a processos interpretativos do investigador, a importância do contexto na compreensão de significados, bem como a compreensão da linguagem oral e escrita do outro.

Independente da natureza da pesquisa qualitativa adotada tais abordagens têm em comum a busca da compreensão e da interpretação do homem como ser único e singular; com a apreensão do ser humano em sua totalidade e do homem como melhor intérprete de si mesmo (VIETTA, 1995, p.34-35).

A arte de interpretação, hermenêutica, foi inicialmente empregada no domínio teológico na interpretação de textos bíblicos. A partir da idade moderna passa a ter o sentido de "arte da compreensão" ou seja, interpretação correta e objetiva dos textos da Escritura (CORETH, 1973).

Por outro lado, a Hermenêutica enquanto forma de interpretação, era utilizada em textos profanos na mitologia e na área jurídica, decorrendo numa regionalização da hermenêutica.

A partir do século XIX há uma tentativa de unificação dessas hermenêuticas especiais ou regionais numa hermenêutica geral ou universal formulada por Friedrich Schleiermacher, que introduz a questão do texto/ contexto (CORETH, 1973).

Para Schleiermacher, a hermenêutica é a arte da compreensão, que não visa ao saber teórico e sim ao saber prático: "a práxis ou a técnica da boa interpretação de um texto falado ou escrito". O autor define a hermenêutica como a "reconstrução histórica e divinatória objetiva e subjetiva de um dado discurso" (CORETH, 1973, p.19).

Wilhelm Dilthey, filósofo alemão, valorizou a teoria da "visão do mundo" em que viver é interpretar o mundo natural. Sua obra "Introdução ao estudo das ciências humanas" (1883), critica a visão positivista da "explicação" sobre o homem buscando a "compreensão" da sua natureza social e histórica. (JAPIASSU \& MARCONDES, 1995, p.73).

Dilthey, apoiando-se em Schliermacher, formula a dualidade de ciências da natureza e ciências do espírito que se distinguem por um método analítico esclarecedor e um procedimento de compreensão descritiva.

"Ao pretender dar um fundamento às ciências particulares do homem, Dilthey postula a criação de novos métodos e de conceitos psicológicos mais sutis adaptados à vida histórica; ademais procura evidenciar, em todas as manifestações humanas, a totalidade da visão psíquica, a ação do homem todo, com sua vontade, sensibilidade $e$ imaginação" (JAPIASSU \& MARCONDES, 1995, p.73).

A compreensão é enfocada por Dilthey sob o ponto de vista interno, ou seja, a partir da psicologia (DILTHEY, 1979). Para ele todas as formas de conhecimento do espírito, enquanto implicar numa relação com a história, teria como pressuposto a capacidade do homem de se transpor para dentro da vida psíquica do outro.

SIEBENEICHLER (1983) ao descrever as idéias inspiradoras da fenomenologia para a hermenêutica filosófica diz que Husserl, filósofo alemão, teve o mérito de recolocar de forma crítica a ciência e a técnica no contexto do sujeito.

Husserl, em seus escritos, tomou como ponto de partida uma ligação intencional entre espírito e mundo, tentando explicar a situação da consciência, do sujeito humano. Por meio do método da "epoché" e da redução fenomenológica encontra um instrumento esclarecedor da consciência, capaz de ultrapassar o psicologismo e o historicismo reinantes na época. Husserl ao tentar encaixar a problemática da consciência individual em um contexto mais amplo verificou que era possível "fundamentar idéias conscientes, recorrendo a uma experiência pré-consciente, não articulada". (SIEBENEICHLER, 1983, p.10).

A partir da herança deixada por Husserl, Heidegger, em sua obra "Ser e Tempo",

"se afasta da fenomenologia de seu mestre Husserl e inicia seu caminho de reflexão sobre o sentido mais profundo da existência humana, bem como sobre as origens da metafisica e o significado de sua influência na formação do pensamento ocidental" (JAPIASSU \& MARCONDES, 1995, p.116).

Heidegger observou que o mundo humano não significa apenas o meio ambiente exterior e nem tão pouco constituía-se de uma construção subjetiva e arbitrária (SIEBENEICHLER, 1983).

Em suas últimas obras, Heidegger explicita que a compreensão se expressa na linguagem e nela se constitui o horizonte histórico da compreensão. "A hermenêutica torna-se, assim, a interpretação da primitiva compreensão do homem em si e do ser" (CORETH, 1973, p.23).

Baseado em Heidegger, de quem foi seu discípulo mais próximo e em seus estudos humanísticos, Gadamer "desenvolveu um interesse filosófico pelo diálogo com a tradição, com as línguas e as culturas distantes e refletiu sobre as condições históricas e filosóficas da compreensão e da interpretação" (HABERMAS, 1987, p.7)

A partir das formulações de Schleiermacher, 
Dilthey e Heidegger, Hans-Georg Gadamer elabora uma teoria filosófica em que a Hermenêutica adquire um status de corrente filosófica.

$\mathrm{Na}$ ótica de SIEBENEICHLER (1983, p.24) Gadamer compreende a Hermenêutica de uma forma mais ampla do que a arte de interpretar. Ela constitui "uma possibilidade no horizonte da mediação entre a verdade do nosso ser e o método da ciência".

A redescoberta fenomenológica do mundo da vida aliada à nova compreensão da linguagem levou a uma troca intensa de idéias entre a fenomenologia e a Hermenêutica filosófica.

Tal redescoberta coloca como possibilidade a mediação entre a razão científica e a razão filosófica, além de possibilitar a constituição da moderna filosofia Hermenêutica de Gadamer e de Paul Ricoeur e da filosofia crítica representada por Habermas. (SIEBENEICHLER, 1983, p.12).

De seus estudos sobre Marx e Freud, Habermas adota como preocupação central uma política emancipatória, refletindo sobre as condições de um "diálogo livre de dominação", a possibilidade de uma "comunicação isenta de coação e violência".

Para o autor, a hermenêutica, mais do que arte de interpretar, ou tecnologia, é crítica (HABERMAS, 1987, p.6-27).

Na perspectiva de RICOUER(1978, p.18), a hermenêutica implica na compreensão dos signos e de si.

"Ao propor religar a linguagem simbólica à compreensão de si, penso satisfazer o desejo mais profundo da hermenêutica. Toda interpretação se propõe a vencer um afastamento, uma distância, entre a época cultural revoluta, à qual pertence o texto, e o próprio intérprete... Portanto, o que ele persegue, através da compreensão do outro, é a ampliação da própria compreensão de si mesmo. Assim, toda hermenêutica é, explícita ou implícitamente, compreensão de si mesmo mediante a compreensão do outro"

Assim, a hermenêutica busca "compreender sentidos" ou seja o conteúdo típico humano que se imprime a qualquer contexto histórico, no qual não existem apenas fatos dados, acontecimentos externos, mas, também, "significação", "sentido" e "valores" (DEMO, 1981, p.249).

Ao se aplicar a uma disciplina a hermenêutica se especifica ganhando feições próprias.

\section{A HERMENÊUTICA E A SOCIOLOGIA FENOMENOLÓGICA}

A Sociologia interpretativa teve suas raízes na teoria de Max Weber e posteriormente recebeu a contribuição de outros estudiosos, a exemplo do fenomenólogo Alfred Schütz.

Ao elaborar o "tipo ideal" a partir de princípios vinculados à história, Weber pretende compreender a ação social como a resultante de forças de relações sociais, ação proveniente do comportamento social que tem um significado subjetivo. Desse modo, coloca o homem como centro das atenções já que a compreensão dos significados se dá no sujeito. Considera "as ações motivadas por sentimentos afetivos e as tradicionais como menos racionais", sendo as ações que se aproximam do tipo racional como as mais compreensíveis (CAPALBO, 1979, p.86).

FREUND (1987, p.73-74) interpretando o pensamento de Weber diz que:

"são racionais a compreensão atual do sentido de uma operação aritmética que efetua o comportamento de um lenhador que abate uma árvore, bem como a compreensão pelos motivos quando vejo uma pessoa ocupada em um trabalho a fim de ganhar sua vida. São irracionais a compreensão atual da cólera ou a compreensão pelos motivos quando a pessoa se serve de uma espingarda para se vingar ou entra em cólera por ciúme... Compreender, pode-se dizer, é captar a evidencia do sentido de uma atividade".

De acordo com SCHÜTZ (1972, p.35) Weber definiu como tarefa da Sociologia não a especulação metafísica e sim uma descrição simples e cuidadosa da vida social. Não uma sociologia enquanto filosofia da existência humana, mas como a ciência particular da conduta humana e suas conseqüências que deve dar conta da compreensão e interpretação da ação social.

Interessado na Sociologia weberiana, Schütz parte para fundamentar a Sociologia da ação e compreensão por meio da análise filosófica da fenomenologia de Husserl.

Segundo o autor a "estrutura significativa do mundo social somente pode deduzir-se a partir das características mais primitivas e gerais da consciência”. Visa, assim, determinar a natureza precisa do fenômeno do significado mediante a análise da função constitutiva, chegando a conclusão de que "a ação é uma vivência guiada por um plano ou projeto que surge da atividade espontânea do sujeito, sendo distinguida de todas as outras vivências por um ato peculiar de atenção". (SCHÜTZ, 1972, p.243)

Schütz propõe a investigação no mundo cotidiano, onde o homem olha para esse mundo do ponto de vista da atitude natural. Tendo nascido nesse mundo que também é social e cultural o homem vive com seus congêneres e dá por certa a existência destes sem questioná-la, assim como dá por certa a existência de objetos naturais. As pessoas interagem e compreendem 
a si próprias e aos outros na realidade social. No entanto, ressalta que somente a olhada reflexiva do observador eleva o conteúdo da consciência do status pré-fenomênico até o fenomênico.

O fenomenólogo se volta para a atitude natural e estuda o que "já se encontra estruturado e de certo modo interpretado, pois a realidade social já possui um sentido para os homens que vivem em seu seio" (CAPALBO, 1979, p.36).

Para SCHÜTZ (1962, p.23-24) a compreensão de uma determinada coisa só é possível ao reduzi-la à atividade que a criou e aos motivos que a originaram, somente sendo possível compreender a atividade humana compreendendo a ação correspondente. Assim, a ação está determinada pelo projeto que inclui o "motivo para" que é o propósito da ação e o "motivo porque" ou seja a razão ou causa da ação.

Para interpretar a ação sob o ponto de vista do ator, ponto de vista subjetivo, Schütz indica um sistema objetivo de análise cujos recursos metodológicos possam alcançar a estrutura subjetiva de sentido, ou seja, a construção do esquema típico-ideal.

Por meio da construção do esquema típico-ideal o autor chega ao "tipo ideal pessoal" que se expressa de certa maneira e tem tais e quais vivências e ao tipo material ou de curso de ação que é o tipo ideal do processo expressivo mesmo (SCHÜTZ, 1972, p.216).

Tais esquemas interpretativos diferem da tipificação que é feita na vida cotidiana, porém devem ser compatíveis não somente com os motivos e as experiências subjetivas do mundo social, como também com a experiência científica em seu conjunto.

No esquema típico-ideal os contextos subjetivos vivenciados diretamente são substituídos de forma sucessiva por uma série de contextos objetivos de significados, chegando-se a um modelo conceitual e nunca a uma pessoa real. Tais modelos devem ser compatíveis com os postulados fundamentais do método científico e ao mesmo tempo responder às exigências do mundo da vida. Desse modo, Schütz aponta os seguintes postulados como requisitos para a construção desses modelos: Postulado da Coerência Lógica, onde as construções típicas são estabelecidas com um alto grau de claridade e nitidez, sendo o esqueleto conceitual totalmente compatível com os princípios da lógica formal. Este postulado garante a validade científica dos modelos construídos. Postulado da Interpretação Subjetiva: para explicar as ações humanas, o pesquisador deve perguntarse que modelo de mente individual é possível construir e que conteúdos típicos são necessários atribuir a ele para explicar fatos observados como resultado da atividade da mente, numa relação compreensível. Assim, tem-se a garantia da significação subjetiva. Segundo o Postulado da Adequação, cada termo de um modelo científico de ação humana deve ser construído de tal maneira que um ato humano efetuado dentro do mundo da vida, por um ator individual, da maneira indicada pela construção típica, seja compreensível tanto para o ator como para seus semelhantes, em termos de interpretação de sentido comum na vida cotidiana. Assim, fica garantida a compatibilidade das construções do cientista social com as construções da experiência do sentido comum na realidade social (SCHÜTZ, 1962, p.67-68).

Para Schütz a tarefa primeira da Sociologia compreensiva consiste em descrever os processos de estabelecimento e interpretação de significado tal como os realizam as pessoas que vivem no mundo social. Ressalta que esta descrição pode ser empírica ou eidética. Pode tomar como tema a pessoa ou o tipo. Pode realizarse em situações concretas da vida cotidiana ou com alto grau de generalidade. Além disso a Sociologia compreensiva pode enfocar os objetos culturais e tratar de compreender o seu significado, aplicando-lhes os esquemas interpretativos.

$\mathrm{O}$ autor elege o esquema subjetivo como o escolhido ao estudar o mundo social tal qual é vivido pelo homem e seus congêneres na atitude natural.

O tipo ideal em Schütz é elaborado a partir da vivência dos sujeitos. É o tipo vivido cujo sentido é obtido num ato vivido.

O tipo vivido concreto possibilita a compreensão das formas significativas de vivência e a compreensão significativa de uma subjetividade comum.

\section{A HERMENÊUTICA E A ANTROPOLOGIA}

A Antropologia, enquanto "a reflexão do homem sobre o homem e sua sociedade" torna-se uma ciência com legitimidade entre outras disciplinas científicas, a partir do século XIX. Nesta época, a antropologia, chamada fundacional ou de gabinete, constituía-se em narrativas e descrições das grandes viagens européias, descobertas de outras sociedades e povos exóticos feitas pelos observadores (viajantes ou missionários) e analisadas pelos pesquisadores em seus gabinetes (LAPLANTINE, 1994).

No século XX a antropologia passa a ser caracterizada pelo trabalho de campo com uma ruptura com a antropologia dita especulativa dando início a antropologia denominada moderna.

$\mathrm{Na}$ antropologia moderna coexistem quatro correntes antropológicas: a racionalista, a estruturalfuncionalista, a culturalista e a interpretativa (CARDOSO DE OLIVEIRA, 1988). A Antropologia Interpretativa ou também pós-moderna, inspira-se na tradição filosófica denominada hermenêutica, tendo em Geertz seu principal representante. 
A Antropologia Interpretativa, pautada no paradigma hermenêutico, apresenta-se como uma crítica às "antropologias tradicionais", reconsiderando verdades que acreditavam eternas (CARDOSO DE OLIVEIRA, 1988, CALDEIRA, 1988).

Nesse novo estilo de se fazer antropologia, a autoridade do investigador é colocada em questão, o saber é negociado entre pesquisador e o nativo, num processo de confrontação de horizontes. A "intersubjetividade, a individualidade e a historicidade" passam a ser exercitadas pelo pesquisador.

“... os horizontes não se excluem de um modo absoluto, mas se interseccionam e muitas vezes se fundem. E propiciam, por conseguinte, o exercício pleno da intersubjetividade (...) nos domínios privilegiados da investigação etnográfica. Investigação que realizava o pesquisador e o pesquisado enquanto individualidade explicitamente reconhecidas, uma vez que a própria biografia deste último pode ser a do primeiro. E ao apresentar a vida do Outro (...), o faz em termos de historicidade, num tempo histórico do qual ele próprio, pesquisador, não se exclui". (CARDOSO DE OLIVEIRA, 1988, p.100101).

Embora todas as correntes dentro da antropologia moderna se empenhem num mesmo esforço interpretativo, Geertz se diferencia na medida em que, na busca do significado simbólico, adota as premissas demandadas pela hermenêutica. Enquanto no estruturalismo, o símbolo é reduzido a um significado, porque pressupõe uma determinada estrutura econômica, de parentesco, entre outras, a antropologia interpretativa de Geertz não aponta um significado e, sim, uma complexidade deles, numa ampla relativização de contextos.

O conceito de cultura de Geertz é essencialmente semiótico, como explica:

"Acreditando, como Max Weber, que o homem é um animal amarrado a teias de significados que ele mesmo teceu, assumo a cultura sendo essas teias e a sua análise; portanto, não como uma ciência experimental em busca de leis, mas como uma ciência interpretativa, à procura do significado”. (GEERTZ, 1989, p.15).

Assim, a Antropologia chamada pós-moderna se preocupa muito mais com os fundamentos do que com as técnicas.

$\mathrm{Na}$ ótica de Geertz não há uma receita para o diálogo na busca da compreensão de significados, comportamentos e ações do outro, o que para ele pressupõe um controle, rigor ou preocupação com a objetividade.

"Olhar as dimensões simbólicas da ação social
(...) não é afastar-se dos dilemas existenciais da vida em favor de algum domínio empírico de formas não emocionalizadas; é mergulhar no meio delas. A vocação essencial da antropologia interpretativa não é responder às questões mais profundas, mas colocar à nossa disposição as respostas que os outros deram (...) e assim incluilas no registro de consultas sobre o que o homem falou" (GEERTZ, 1989, p.40-41).

Para GEERTZ (1989) uma etnografia é uma "descrição densa" o que implica na busca da profundidade e da contextualização dos significados.

A descrição etnográfica na concepção de GEERTZ (1989, p.31) é interpretativa. “... o que ela interpreta é o fluxo social e a interpretação envolvida consiste em tentar salvar o "dito" num tal discurso da sua possibilidade de extinguir-se e fixá-lo em formas pesquisáveis”.

Não há uma univocidade de concepção hermenêutica enquanto raiz filosófica da Antropologia Interpretativa,

"ao contrário, o que se verifica é uma verdadeira dispersão de influências nessa antropologia que se pretende nova. Nem a "hermenêtica ontológica" de Heidegger e Gadamer, nem a "hermenêutica metódica" de Betti ou de Hirsch, nem a "hermenêtica fenomenológica" de Ricoeur (e muito menos a "hermenêutica clássica" de Schleiermacher e Dilthey) dominam aquilo que prefiro chamar de "consciência hermenêutica" na Antropologia "pós-moderna" (CARDOSO DE OLIVEIRA, 1988, p.97).

\section{CONSIDERAÇÕES FINAIS}

Uma das tradições na Sociologia e Antropologia se inspira nos fundamentos da Filosofia da compreensão alemã, representada por Weber na Sociologia e em diferentes concepções hermenêuticas, na Antropologia.

A hermenêutica enquanto paradigma filosófico tem fundamentado as pesquisas qualitativas da enfermagem.

Ao considerar as situações cotidianas do enfermeiro no contexto da saúde, buscando o ponto de vista dos sujeitos, sobre suas condições no processo saúde-doença, esse profissional tem aproximado mais as pesquisas da assistência de enfermagem, voltando-se à compreensão/interpretação dos fenômenos pesquisados.

A compreensão e interpretação do fenômeno que interessa ao enfermeiro se dá "em sua natureza material e significativa e não em sua natureza formal e estrutural que caberia à ciência e aos cuidados médicos"(CAPALBO, 1994, p.196). 
Acreditamos que por meio da hermenêutica vislumbramos a possibilidade de compreender os significados atribuídos pelos sujeitos à condição existencial de estar no mundo e, por meio de sua linguagem, em relatos, chegar a compreensão de sua ação.

$\mathrm{O}$ homem revela a realidade por meio da linguagem oral ou escrita e pela interpretação da linguagem o pesquisador chega aos aspectos significativos essenciais para a compreensão do ser. Portanto, a linguagem pode ser um elemento mediador que permite essa compreensão/interpretação, tanto dos processos cognitivos individuais, quanto dos aspectos sociais e culturais.

Adotar na enfermagem pesquisas de natureza interpretativa representa, cada vez mais, a possibilidade para que os enfermeiros analisem fenômenos no cotidiano da saúde, a partir do ponto de vista de quem o vivencia.
Grande parte das pesquisas de enfermagem enfoca questões do cotidiano, buscando significados socialmente compartilhados. Concordamos com LOWENBERG (1993) quando afirma que a adoção de abordagens interpretativas é um caminho promissor para a enfermagem, em suas atividades de pesquisa. Da mesma forma, enveredar por esse caminho possibilitará que a enfermagem participe do diálogo atual entre as Ciências Sociais e Humanas.

É importante não definir os limites destas abordagens de uma forma rígida, pois estamos numa fase de "transição revolucionária"(LOWENBERG, 1993).

Por outro lado, ao elaborar projetos de pesquisa de natureza interpretativa sugerimos que se reserve um espaço para mudanças, abrindo a possibilidade de redefinir o caminho a percorrer, a partir da própria experiência. Experiência que é única e imprevisível, visto que se refere ao diálogo com o outro, à interação humana.

\section{HERMENEUTIC AND QUALITATIVE RESEARCH ON NURSING}

The study review the literature about hermeneutics as a foundation for ethnographic and phenomenological research.

KEY WORDS: interpretative research, hermeneutic, phenomenology, anthropology

\section{LA HERMENÉUTICA Y LAS INVESTIGACIONES CUALITATIVAS EN ENFERMERÍA}

El estudio presenta una revisión de la literatura sobre el paradigma hermenéutico como fundamentación de las investigaciones etnográficas y fenomenológicas.

TÉRMINOS CLAVES: investigación interpretativa, hermenéutica, fenomenología, antropología

\section{REFERÊNCIAS BIBLIOGRÁFICAS}

01. BLEICHER, J. Hermenêutica contemporânea. Rio de Janeiro: Edições 70, 1992.

02. CALDEIRA, T.P. do R. A presença do autor e a pósmodernidade. Novos Estudos, n.21, p.133-57, julho 1988 .

03. CAPALBO, C. Considerações sobre o método fenomenológico e a enfermagem. Rev. Enferm. UERJ, v.2, n.2, p.192-197, 1994.

04. CAPALBO, C. Metodologia das ciências sociais: a fenomenologia de Alfred Schütz. Rio de Janeiro: Antares, 1979.

05. CARDOSO DE OLIVEIRA, R. Sobre o pensamento antropológico. Rio de Janeiro: Tempo Brasileiro, 1988.

06. CORETH, E. Questões fundamentais de hermenêutica. São Paulo: EPU/EDUSP, 1973.

07. DEMO, P. Metodologia científica em ciências sociais. 3. ed. São Paulo: Artes, 1981.
08. DILTHEY, W. Essência da filosofia. Lisboa: Presença, 1979.

09. FREUND, J. Sociologia de Max Weber. 4. ed. Rio de Janeiro: Forense Universitária, 1987.

10. GEERTZ, C. A interpretação das culturas. Rio de Janeiro: Guanabara, 1989.

11. JAPIASSU, H.; MARCONDES, D. Dicionário básico de filosofia. 2. ed. Rio de Janeiro: Zahar, 1995.

12. HABERMAS, J. Dialética e hermenêutica. Porto Alegre: L\&PM, 1987.

13. LAPLANTINE, F. Aprender antropologia. 8. ed. São Paulo: Brasiliense, 1994.

14. LOWENBERG, J. Interpretive research methodology: broadening the dialogue. Adv. Nurs. Sci., v.16, n.2, p.57-69, 1993.

15. RICOUER, P. O conflito das interpretações: ensaios de hermenêutica. Rio de Janeiro: Imago, 1978.

16. SCHÜTZ, A. El problema de la realidad social. Buenos Aires: Amorrortu, 1962. 
17. SCHÜTZ, A. Fenomenologia del mundo social: introdución a la sociologia compreensiva. Buenos Aires: Paidós, 1972.

18. SIEBENEICHLER, F.B. Fenomenologia e hermenêutica. In: CAPALBO, C. Fenomenologia e hermenêutica. Rio de Janeiro: Âmbito Cultural, 1983. Cap. 1, p.9-34.
19. VIETTA, E.P. Configuração triádica, humanistaexistencial-personalista: uma abordagem teórico-metodológica de aplicação nas pesquisas de enfermagem psiquiátrica e saúde mental. Rev. latino am. enfermagem, v. 3, n. 1, p.31-43, 1995. 